\title{
The shocking pink dragon millipede, Desmoxytes purpurosea, a colourful new species from Thailand (Diplopoda: Polydesmida: Paradoxosomatidae)
}

\author{
HENRIK ENGHOFF $^{1,3}$, CHIRASAK SUTCHARIT ${ }^{2} \&$ SOMSAK PANHA $^{2,3}$ \\ ${ }^{\prime}$ Natural History Museum of Denmark, University of Copenhagen, Universitetsparken 15, DK-2100 Copenhagen $\emptyset$, Denmark. \\ E-mail: henghoff@snm.ku.dk \\ ${ }^{2}$ Animal Systematics Research Unit, Department of Biology, Faculty of Science, Chulalongkorn University, Phyathai Road, Patumwan, \\ Bangkok 10330, Thailand. E-mail: somsakp@sc.chula.ac.th \\ ${ }^{3}$ Corresponding authors
}

\begin{abstract}
A shocking pink, very spiny new species of "dragon millipede", Desmoxytes purpurosea sp.n., is described from Thailand, Uthaithani province. Its behaviour suggests that its colouration is aposematic, like that of some bright red congeners. Relations of the new species to congeners are discussed.
\end{abstract}

Key words: taxonomy, aposematic, Uthaithani province

\section{Introduction}

The striking, spiny "dragon millipedes" of the genus Desmoxytes are known from a large area in South East Asia, from south-eastern China south through Vietnam, Thailand and Myanmar. Twenty-three species are known from this area. One of these, D. planata (Pocock, 1895) occurs not only in Southeast Asia but has also been recorded from Sri Lanka, the Andaman, Seychelles and Fiji islands and has further been encountered in quarantine in soil around plants from Java and Sri Lanka (Shelley \& Lehtinen 1998, Shelley et al. 1998).

The genus was revised by Golovatch \& Enghoff (1994), and Nguyen Duc Anh et al. (2005) described further new species from Vietnam. Mesibov (2006) described the similar genus Desmoxytoides from Australia and emphasized that the circumscription of Desmoxytes remains questionable. For the time being, we adhere to the somewhat loose generic diagnosis given by Golovatch \& Enghoff (1994). Apart from D. planata which beyond doubt owes its large distribution to anthropochore dispersal, all known species of Desmoxytes are known from only one or at most a few localities. The described species of "dragon millipedes" are listed in Table 1.

The species described in the present paper is remarkable for its striking, shocking pink colouration. At 3 $\mathrm{cm}$ in length, it is also among the largest species in its genus. At the type locality, many specimens were seen sitting openly on the ground and vegetation during daytime. The stark bright colour no doubt is aposematic, warning would-be predators of a spiny, toxic animal. Millipedes of the order Polydesmida produce hydrogen cyanide in their defensive glands (Eisner et al. 1978), and living specimens of the new species gave off the typical almondlike smell associated with cyanide production. We think that such an unusually coloured, conspicuous millipede deserves more than a Latin name and suggest calling it "The shocking pink dragon millipede" (in Thai: Mangkorn Chomphoo).

The new species was collected from a unique ecosystem. Hup Pa Tard is a Permian limestone cavern cov- 
ered with vegetation dominated by the palm Arenga pinnata. This palm species has its vernacular Thai name as "Tard or Taw" which is the origin of the name of the site. It was suggested by geologists that Hup Pa Tard was originally a cave but that later the roof collapsed, resulting in the present cavernous mountain with high humidity throughout (Department of National Parks, Thailand 2004). The specific habitat characteristics favour many kinds of soil animals such as the land snails Cyclophorus volvulus (Müller, 1784), Alycaeus sp., Streptaxis sp., as well as some microsnails. Other rare animals are also reported living in this habitat such as Siamese fireback pheasant, Lophlura diardi (Bonaparte, 1856); various kinds of squirrel and the serow Capricornis sumatraensis Bechstein, 1799. Hup Pa Tard seems to be a very good place for millipedes - together with the new dragon millipede numerous other species were collected, including, i.a., species of the families Siphonorhinidae, Polyzoniidae, Pachybolidae and Harpagophoridae, the latter being represented by the common species Thyropygus allevatus (Karsch, 1881).

TABLE 1. Known species of "dragon millipedes". See Golovatch \& Enghoff (1994), for synonymy.

Genus Desmoxytes Chamberlin, 1923

D. acantherpestes Golovatch \& Enghoff, 1994

Thailand

D. aspera (Attems, 1937)

Vietnam

D. cattienensis Nguyen Duc Anh et al., 2005

Vietnam

D. cervaria (Attems, 1953)

Vietnam

D. cervina (Pocock, 1895)

Myanmar

D. cornutus (Zhang \& Li, 1982)

China

D. delfae (Jeekel, 1964)

Thailand

D. draco (Cook \& Loomis, 1924)

China

D. enghoffi Nguyen Duc Anh et al., 2005

Vietnam

D. gigas Golovatch \& Enghoff, 1994

Thailand

D hostilis Golovatch \& Enghoff, 1994

Vietnam

D. jeekeli Golovatch \& Enghoff, 1994

Thailand

D. longispina (Loksa, 1960)

China

D. minutuberculata (Zhang, 1986)

China

D. pilosa (Attems, 1937)

Vietnam

D. planata (Pocock, 1895)

widespread

D. proxima Nguyen Duc Anh et al., 2005

Vietnam

D. pterygota Golovatch \& Enghoff, 1994

Thailand

D. rubra Golovatch \& Enghoff, 1994

Thailand

D. specialis Nguyen Duc Anh et al., 2005

Vietnam

D. spectabilis (Attems, 1937)

Vietnam

D. taurina (Pocock, 1895)

Myanmar

D. terae (Jeekel, 1964)

Malaysia, Thailand

Genus Desmoxytoides Mesibov, 2006

D. hasenpuschorum Mesibov, 2006

Australia

Specimens of the new dragon millipede were found sitting and moving on the limestone rocks and on the leaves of Arenga pinnata palms, almost everywhere in moist areas of this locality. After rain they occur in large numbers. We have found mainly adult animals so far even though we searched various kinds of litterthe juveniles presumably live in the soil. 


\section{Desmoxytes purpurosea sp.n.}

Figs 1-2.

Material examined: HOLOTYPE male Thailand, Hup Pa Tard, Tam Pratun Non-hunting area, Department of National Parks, Lansak district, Uthaithani province at $15^{\circ} 22.602^{\prime} \mathrm{N} 99^{\circ} 37.346^{\prime} \mathrm{E}, 28$.viii.2006, S. Panha, H. Enghoff, P. Pimwichai and C. Sutcharit leg. (Museum of Zoology, Chulalongkorn University, Bangkok). Paratypes: 16 males, 30 females, same data as holotype ((Museum of Zoology, Chulalongkorn University, Bangkok, 4 males, 3 females Natural History Museum of Denmark, University of Copenhagen).

Etymology: The species epithet is a composite Latin adjective, meaning "purple-pink".

Diagnosis: Paraterga winglike. Gonopods strongly condensed. Male femora 5 and 6 humped. Similar in these respects to D. cervina (Pocock, 1895), D. delfae (Jeekel, 1964), D. planata (Pocock, 1895), D. pterygota Golovatch \& Enghoff, 1994, and D. rubra Golovatch \& Enghoff, 1994. Differs from these species by having $3+3$ posterior spines on midbody metaterga instead of $2+2$, and by the combination of red-pink colour and larger size.

Description: Length ca. $3 \mathrm{~cm}$ (both sexes), width of midbody pro- and metazoa 1.8 and $3.2 \mathrm{~mm}$ (male) / 2.5-2.6 and $4.0 \mathrm{~mm}$ (female). Colour of living animals (Fig. 1) purple to shocking pink, head brownish, antennae black; colour retained after 10 days in alcohol but faded to light brown after 10 months.

Head quite densely setose except on almost naked vertex, narrower than collum. Epicranial suture distinct. Antennae very long, reaching back to body ring 8 (male) or 6 (female).

Collum as broad as body ring 2 , with 3 transverse rows of setae, $4+4$ anterior, $1+1$ intermediate, $2+2$ posterior, lateral setae of posterior row displaced anteriad almost halfway to intermediate row.
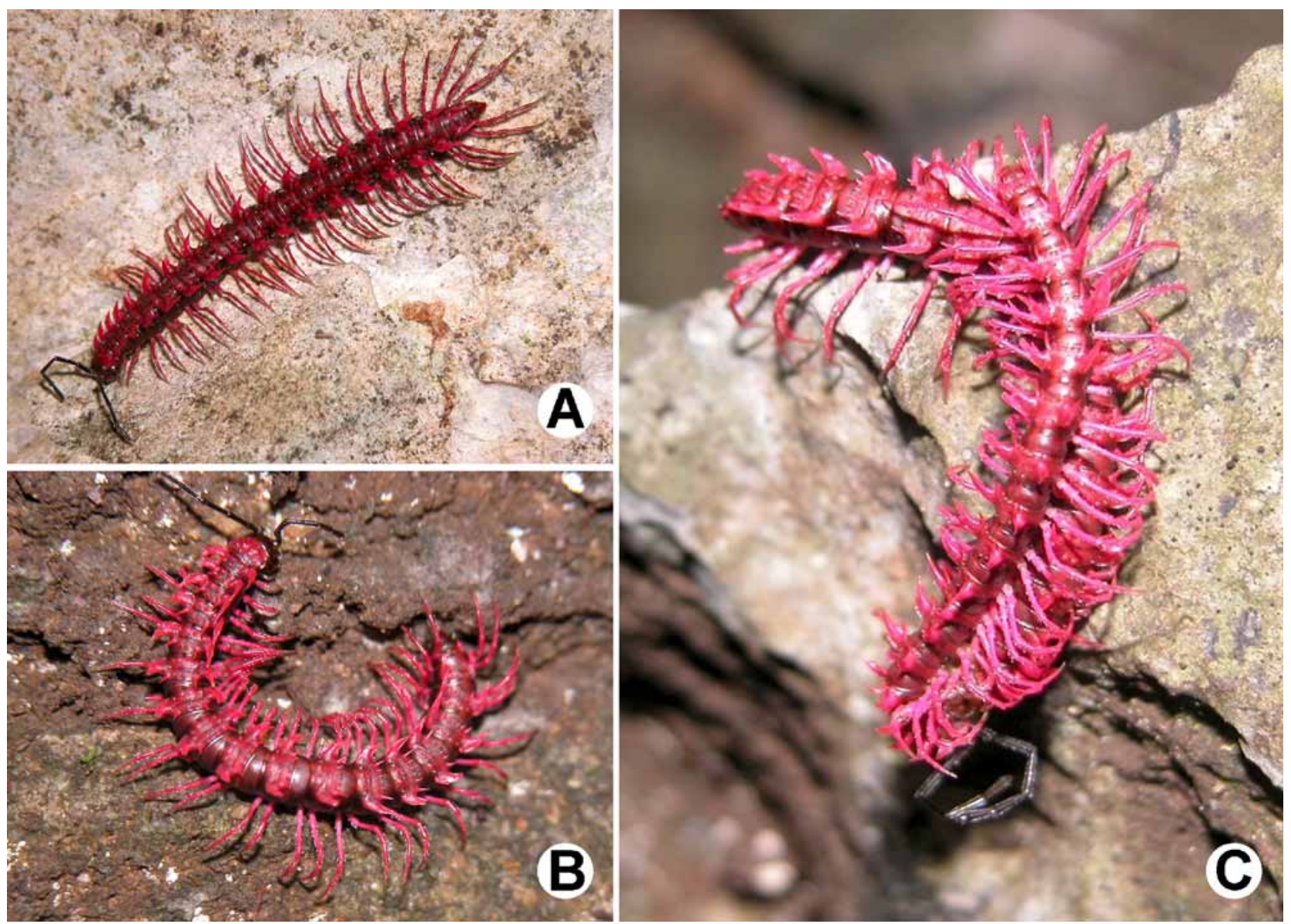

FIGURE 1. A and B: two different males. C: mating couple, male on top. Photographs by S. Panha. 


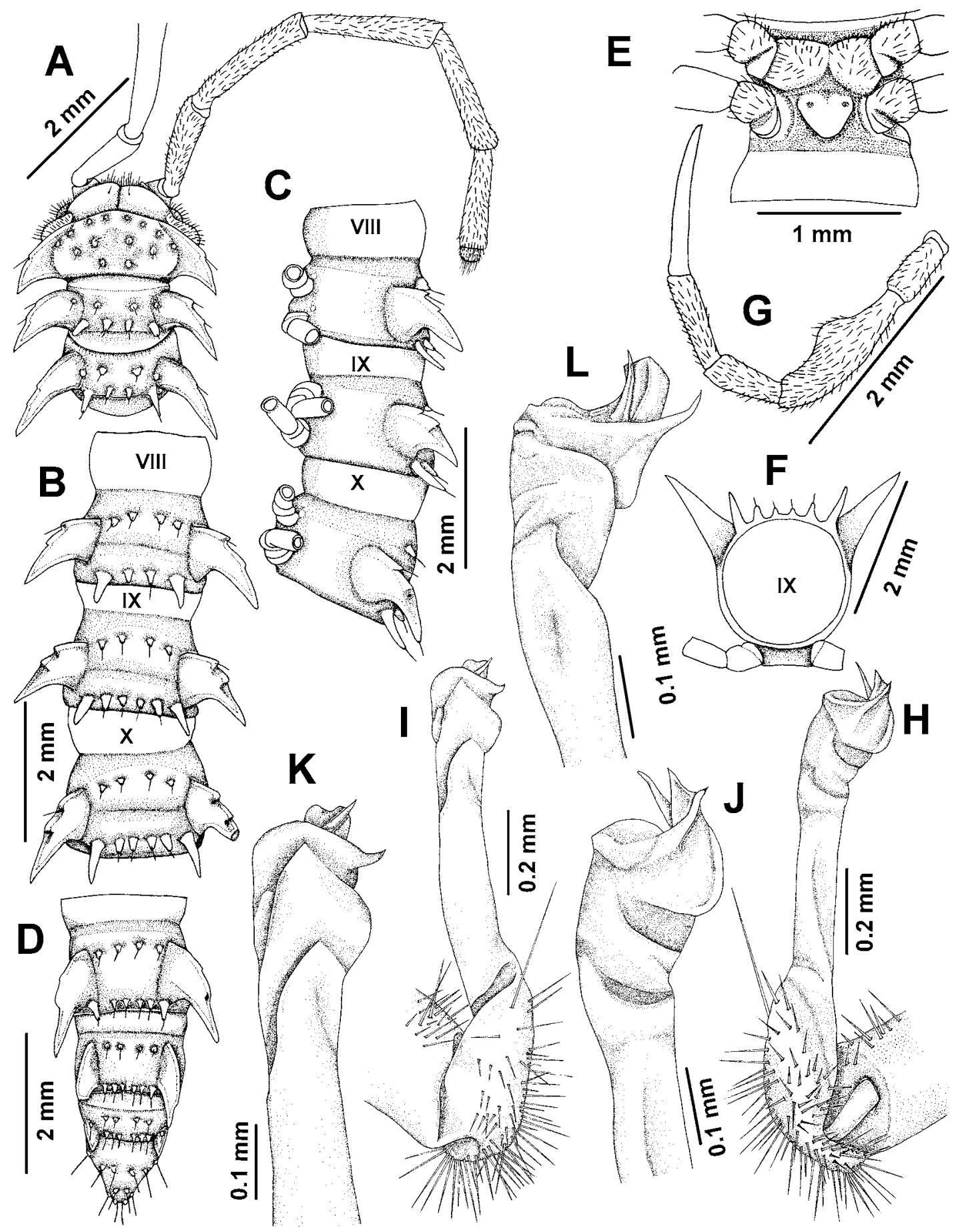

FIGURE 2. A-C, D: body rings of male, A, B, D: dorsal view, C: lateral view. E: ventral view of male body ring 5, showing protuberance between legs 4. F: body ring of male, posterior view. G: male leg 6, showing humped femur. H-L: right gonopod, H, J: mesal view, I, K: lateral view, L: ventral view.

Body parallel-sided from ring 7 to 15 , anteriorly and especially posteriorly gradually tapering. Metaterga (Fig. 2 A-D, F) with two transverse rows of setiferous spines; metaterga 2-8 with $2+2$ anterior and $2+2$ posterior spines, lateral spines of posterior rows much longer than the others; metagerga 9-17 with $2+2$ small, rosethornlike anterior spines and $3+3$ posterior spines, lateral ones very long, intermeditate ones shorter, mesal ones shortest. Metatergum 18 with $2+2$ anterior and $3+3$ (or $3+4$ ) posterior spines, all posterior spines of equal length; metatergum 19 with $2+2$ anterior and $2+2$ (or $2+3$ ) posterior setae which are not on spines or tubercles. 
Axial line not visible. Paraterga wing-shaped, tip bent posteriad. Paraterga on collum almost horizontal, with one setiferous notch on anterior edge. Paraterga of rings 2-19 longer, directed obliquely upwards at ca. $45^{\circ}$ in anterior part of body, becoming gradually more horizontal towards the rear, on rings 17-19 directed straight posteriad, anterior edge of paraterga 2-18 with 2 small setiferous notches. Surface finely shagreened, slightly more coarsely so on metazona (but not on paraterga). Suture between pro- and metazona smooth. Ozopores visible from above, located in distalmost notch on anterior paratergal edge. Transverse sulcus evident on metaterga 5-18. Pleurosternal carinae poorly developed on body rings 2-3, absent from others.

Preanal projection (=epiproct, Fig. 2 D) simple, conoid, with a pair of tiny setiferous lateral knobs near tip. Subanal scale trapezoid, posterior margin very slightly convex between pair of setae.

Sterna quite densely setose. A simple transverse, trapezoid, sparsely setose lamina between male coxae 4 (Fig. 2 E). Distal margin of lamina sometimes slightly concave. A pair of round structure (pores?, cf., e.g. $D$. terae (Jeekel, 1964), Golovatch \& Enghoff 1994) at base of posterior side of lamina.

Legs very long and slender as seen from above, projecting laterad from body by maximum body width in females, and even more than maximum body width in males. Male femora 5 and 6 distinctly humped (Fig. 2 $\mathrm{G})$.

Gonopods (Fig. 2 H-L). Shaft very slender, almost straight, postfemoral part strongly condensed.

\section{Discussion}

In the key of Golovatch \& Enghoff (1994), D. purpurosea runs to couplet 7 which separates D. aspera (Attems, 1937) and D. planata (Pocock, 1895). It differs from these species not only by its colour, but also by being considerably larger and from $D$. planata further by having $3+3$ posterior spines on the metaterga, from $D$. aspera further by having modified femora on male legs 5 and 6 . We have not re-run the phylogenetic analysis done by Golovatch \& Enghoff (1994), considering that comparable information on the species described by Nguyen Duc Anh et al. (2005) cannot be extracted to a sufficient degree from the species descriptions. It may be noticed, however, that in Golovatch \& Enghoff's table 1 which groups the Desmoxytes species known to them according to shape of paraterga, degree of gonopodal condensation, and modifications of male femora, D, purpurosea groups with two other aposematic species, D. delfae (Jeekel, 1964) and D. rubra Golovatch \& Enghoff, 1994, see below. It is also with these two species that $D$. purpurosea shares the highest number of characters among the 24 binary ones used by Golovatch \& Enghoff for their phylogenetic analysis. If scored for these characters D. purpurosea obtains the score 011000010000000111110011 , and it shares 22 characters with $D$. delfae and D. rubra. These two species appear as sister-groups in Golovatch \& Enghoff's preferred cladogram, with $D$. planata being sister to the couple. We feel confident in stating that $D$. purpurosea is closely related with these three species ( $D$. planata is even purplish pink in life, although not so strikingly as $D$. purpurosea).

As mentioned in the introduction, the striking purple colouration of D. purpurosea is probably aposematic. The same is probably true of its bright red congeners $D$. rubra and $D$. delfae which have both been observed sitting openly on the vegetation (Golovatch \& Enghoff 1994).

Other species of Desmoxytes have different, but similarly striking colours, see, for example, the photograph of an undescribed species from Thailand at http://animaldetective.com/Desmoxytes.html.

\section{Acknowledgements}

This research was funded by BRT Program (TRF/BIOTECH - Thailand Biodiversity Research and Training Program) under the BRT-Millipede-Earthworm Project. We thank Ruengrit Promdam who first introduced the 
dragon millipede and type locality to SP. Thank also to Piyatida Pimvichai who took part in the fieldwork when the type series was collected. We express our sincere gratitude to the staff of Hup Pa Tard, the unique limestone cavern of Uthaithani province, for their kind help until the research was possible.

\section{References}

Department of National Parks, Thailand (2004) Hup Pa Tard, Uthaithani. Year Report on biodiversity resources conservation, $34 \mathrm{pp}$. (in Thai).

Eisner, T., Alsop, D., Hicks, K. \& Meinwald, J. (1978) Defensive scretions of millipeds. Handbook of Pharmacology, 48, 41-72.

Golovatch, S.I. \& Enghoff, H. (1994) Review of the dragon millipedes, genus Desmoxytes Chamberlin, 1923 (Diplopoda, Polydesmida, Paradoxosomatidae). Steenstrupia, 20, 45-71.

Mesibov, R.(2006) Dirt-encrusted and dragon millipedes (Diplopoda: Polydesmida: Paradoxosomatidae) from Queensland, Australia. Zootaxa, 1354, 31-44.

Nguyen Duc Anh, Golovatch, S.I. \& Anichkin, A.E. (2005) The dragon millipedes in Vietnam (Polydesmida: Paradoxosomatidae, genus Desmoxytes Chamberlin, 1923). Arthropoda Selecta, 14, 251-257.

Shelley, R.M., Bauer, S.B. \& Swift, S.F. (1998) The millipede family Paradoxosomatidae in the Hawaiian islands (Diplopoda: Polydesmida). Bishop Museum Occasional Papers, 56, 43-53.

Shelley, R.M. \& Lehtinen, P.T. (1998) Introduced millipeds of the family Paradoxosomatidae on Pacific Islands (Diplopoda: Polydesmida). Arthropoda Selecta, 7, 81-94. 